\title{
Suppression of Graft-Versus-Host Disease and Amplification of Graft-Versus-Tumor Effects by Activated Natural Killer Cells after Allogeneic Bone Marrow Transplantation
}

\author{
Osamu Asai, ${ }^{\star}$ Dan L. Longo, ${ }^{\S}$ Zhi-Gang Tian, ${ }^{\ddagger}$ Ronald L. Hornung, ${ }^{\ddagger}$ Dennis D. Taub, ${ }^{\S}$ Francis W. Ruscetti, ${ }^{*}$ \\ and William J. Murphy \\ *Laboratory of Leukocyte Biology, ${ }^{\ddagger}$ Intramural Research Support Program, SAIC-Frederick, National Cancer Institute-Frederick Cancer \\ Research and Development Center, Frederick, Maryland 21702; and ${ }^{\S}$ National Institute on Aging, Gerontology Research Center, \\ Baltimore, Maryland 21224
}

\begin{abstract}
Bone marrow transplantation (BMT) is currently used for the treatment of a variety of neoplastic diseases. However, significant obstacles limiting the efficacy of allogeneic BMT are the occurrence of graft-versus-host disease (GvHD) and tumor relapse. Natural killer (NK) cells exert a variety of immunologic and homoeostatic functions. We examined whether adoptive transfer of activated NK cells of donor type would prevent GvHD after allogeneic BMT in mice. Lethally irradiated $\mathrm{C} 57 \mathrm{BL} / 6\left(\mathrm{H}-2^{\mathrm{b}}\right)$ mice, were transplanted with MHC incompatible BALB/c (H-2 $\left.{ }^{\mathrm{d}}\right)$ bone marrow cells and spleen cells and rapidly succumbed to acute GvHD. In contrast, mice that also received activated NK cells of donor type exhibited significant increases in survival. In determining the mechanism by which the NK cells prevented GvHD, mice were concurrently treated with a neutralizing antibodies to the immunosuppressive cytokine TGF $\beta$. Anti-TGF $\beta$ completely abrogated the protective effects of the activated donor NK cells indicating that TGF $\beta$ plays an important role in the prevention of GvHD by NK cells. We then examined whether activated NK cells of donor type after allogeneic BMT would induce graft-versus-tumor (GvT) effects without GvHD in mice bearing a murine colon adenocarcinoma (MCA-38). $10 \mathrm{~d}$ after receiving the tumor, in which the mice had demonstrable lung metastases, recipients received an allogeneic BMT with or without activated NK cells. Administration of activated NK cells resulted in significant GvT effects after allogeneic BMT as evidenced by increases in median survival and fewer lung metastasis. No evidence of GVHD was detected compared with recipients receiving spleen cells alone which also developed fewer lung metastases but in which all had succumbed to GVHD. Thus, our findings suggest that adoptive immunotherapy using activated donor NK cells combined with allogeneic BMT inhibits GvHD and promotes GvT in advanced tu-
\end{abstract}

Address correspondence to William J. Murphy, Intramural Research Support Program, SAIC-Frederick, National Cancer Institute-Frederick Cancer Research and Development Center, Frederick, MD 21702, Building 567, Room 209, Frederick, MD 21702. Phone: 301846-5443; FAX: 301-846-6107; E-mail: murphyw@ncifcrf.gov

Received for publication 22 July 1997 and accepted in revised form 24 February 1998.

The Journal of Clinical Investigation

Volume 101, Number 9, May 1998, 1835-1842

http://www.jci.org mor-bearing mice. These results also suggest that GvT and GvHD can be dissociable phenomena. (J. Clin. Invest. 1998. 101:1835-1842.) Key words: NK cell • graft-versus-host disease $\cdot$ bone marrow transplantation $\bullet$ immunotherapy $\bullet$ cytokines

\section{Introduction}

Bone marrow transplantation $(\mathrm{BMT})^{1}$ is currently used to treat patients with various nonneoplastic and neoplastic diseases including hematologic malignancies and solid tumors that remain sensitive to high-dose myeloablative, but not conventional, doses of chemotherapy (1). However, significant obstacles still limit the efficacy of this procedure. These include: the occurrence of graft-versus-host disease (GvHD) in allogeneic BMT, the failure of the marrow to engraft, the susceptibility of patients to opportunistic infections after the transplant, and, when used for the treatment of cancer, the recurrence of neoplastic disease (1-3).

GvHD is caused by an attack of donor T cells against alloantigens of the recipient (4). The life-threatening complication is often the profound immune suppression that accompanies GvHD (4). Removal of the donor $T$ cells in the bone marrow graft has been performed which decreases the incidence of acute GvHD (2-4). Unfortunately, T cell depletion is also associated with increased incidences of disease relapse and failure of the marrow to engraft (3-6).

Relapse of malignancies after BMT remains a significant problem in BMT and further dose escalation of the conditioning regimen is limited by toxicities to nonhematopoietic organs such as the lungs and digestive system (3). One method that might augment the antitumor effects of the myeloablative therapy of the conditioning regimen is use of adoptive immunotherapy to remove the residual tumor. The occurrence of a graft versus tumor (GvT) effect after allogeneic BMT appears capable of offering additional antitumor effects if the GvHD that also occurs can be controlled. Unfortunately, many of the means that are used to control GvHD (i.e., immunosuppression) also inhibit GvT. As the majority of spontaneous tumors are typically nonimmunogeneic, the elicitation of natural killer (NK) cell-mediated effector functions (i.e., MHC unrestricted cytotixicity) may be helpful in inducing clinically significant antitumor responses after BMT.

NK cells exert a variety of immunologic and homeostatic

1. Abbreviations used in this paper: BMC, bone marrow cells; BMT, bone marrow transplantation; GvHD, graft-versus-host disease; GvT, graft-versus-tumor; NK, natural killer; rhIL-2, human recombinant IL-2; SC, splenocyte. 
functions both in vitro and in vivo in addition to their wellcharacterized antitumor effects (7). NK cells have also been demonstrated to be both beneficial and deleterious in murine bone marrow transplantation studies, depending on their genotype and activation status $(7,8)$. Upon activation, NK cells produce a variety of regulatory cytokines including $\mathrm{TGF}_{1}$, IFN $\gamma, \mathrm{TNF} \alpha$, IL-1 $\beta$, granulocyte-colony stimulating factor (G-CSF), and GM-CSF $(8,9)$. We have recently shown that transfer of activated NK cells of donor type improved allogeneic marrow engraftment without inducing GvHD in mice (10). Therefore we have examined the effects of recombinant human IL-2 (rhIL-2) activated NK cells of donor-type in the setting where allogeneic BMCs are supplemented with allogeneic T cells to ascertain if activated NK cells could also actively prevent the occurrence of GvHD without compromising the antitumor effects. The data presented here demonstrate that rhIL-2-activated NK cells of donor type can directly inhibit the occurrence of GvHD while still promoting GvT effects in advanced tumor-bearing mice.

\section{Methods}

Mice. C57BL/6J (B6, H-2 $)$, BALB/c (H-2 $\left.{ }^{\mathrm{d}}\right)$, C.B.-17 scid/scid (SCID, $\left.\mathrm{H}-2^{\mathrm{d}}\right), \mathrm{C} 3 \mathrm{H} / \mathrm{Hej}\left(\mathrm{C} 3 \mathrm{H}, \mathrm{H}-2^{\mathrm{k}}\right)$ were obtained from the Animal Production Area, National Cancer Institute-Frederick Cancer Research and Development Center (NCI-FCRDC), Frederick, MD. Mice were used at 8-12 wk of age and were kept under specific pathogen-free conditions; SCID mice were housed in microisolater cages and all food, water, and bedding were autoclaved before use. SCID mice received trimethoprim/sulfamethoxazole (40 mg trimethoprim and $200 \mathrm{mg}$ sulfamethoxazole per $320 \mathrm{ml}$ drinking water) in suspension in their drinking water.

Propagation of NK cells and MCA-38 tumor cells. NK cells were prepared from the back bones, tibias, femurs, and spleens of SCID mice in a procedure described previously $(8,10)$. The cell suspension was cultured in $5,000 \mathrm{IU} / \mathrm{ml}$ of human recombinant interleukin-2 (rhIL-2, a gift from Hoffmann-LaRoche, Nutley, NJ) for $6 \mathrm{~d}$ before use. The MCA-38 cell line (a colon adenocarcinoma induced with 1,2dimethylhydrazine in B6 mice was passaged subcutaneously. The dissociation of MCA-38 cells derived from solid tumor in the subcutaneous site was accomplished with $0.25 \%$ trypsin- $0.2 \%$ EDTA followed by filtration through a No. 8 nylon mesh.

In vivo bone marrow transplant model and tumor studies. On the day of BMT (day 0), B6 mice were exposed to 1,000 cGy total body irradiation from a ${ }^{137} \mathrm{Cs}$ gamma irradiation source, and then the irradiated mice in some groups were injected with $2 \times 10^{7}$ activated NK cells of donor type intraperitoneally (i.p.). $4 \mathrm{~h}$ later, the mice received $1 \times 10^{7} \mathrm{BALB} / \mathrm{c}$ bone marrow cells (BMC) intravenously (i.v.) with or without BALB/c splenocytes (SC, $2 \times 10^{7}$ cells i.v.) as a source of allogeneic T cells. Some groups received $5 \times 10^{4} \mathrm{IU}$ of rhIL-2 i.p. on day 0,1 , and 2 . Some groups received $80 \mu \mathrm{g}$ of anti-TGF $\beta$ monoclonal antibody capable of neutralizing mammalian isotypes of TGF $\beta$ (1D11.16) or control antibody i.p. on day 0, 2, and 4 (11). In some experiments mice received 1.0 or $0.1 \mu \mathrm{g}$ of $\operatorname{rhTGF} \beta$ i.p. (Genzyme Corp., Boston, MA) on day 0, 1, 2, and 3. In the tumor studies, MCA38 tumor cells $\left(1 \times 10^{5}\right.$ cells $)$ were injected into B6 mice intravenously $10 \mathrm{~d}$ before BMT. On day 10 the BMT was performed as described previously and mice were monitored for effects on survival. On day 14 after BMT, the lungs of the mice were harvested, placed into Bouin's solution, and then the tumor nodules on the lung surface were counted by microscopy. Animals required at least four of the usual indicators of GvHD: alopecia (extensive hair loss), scleroderma, weight loss, splenomegaly, severe diarrhea, and bleeding or inflammation at the eyes, nose, or mucous membranes to meet the diagnostic criteria of GvHD. Progressive tumor growth was usually manifested by tumor nodules on the lungs. Moribund mice were killed and necropsy was performed to determine cause of death. All experiments were performed at least 3 times with 10 mice per group and a representative experiment being shown.

Cytotoxicity assay and proliferation assay. The tumor cells were labeled by incubation for $1 \mathrm{~h}$ at $37^{\circ} \mathrm{C}$ with $\mathrm{Na}^{51} \mathrm{CrO}_{4}$ (Du Pont-NEN, Boston, MA, sp act: $511 \mathrm{mCi} / \mathrm{mg}$ ). After this incubation, the target cells were washed, and plated into the well of a round-bottom 96-well plate (model 25850; Corning Glass Works, Corning, NY) at a concentration of $5 \times 10^{3}$ cells per well. Effector cells (IL-2-activated SCID NK cells) obtained from $6 \mathrm{~d}$ in vitro cultured with rhIL-2 were added to each well to achieve effector/target $(\mathrm{E} / \mathrm{T})$ cell ratios of 30:1, 10:1, and 3:1. Four replicate wells were used in these assays. After standard $4 \mathrm{~h}$ incubation, the supernatant were harvested and analyzed on a gamma counter (model 5500; Beckman Instruments, Irvine, CA). The percentage specific lysis was calculated as followed:

percentage specific lysis $=\frac{\mathrm{CPM}(\exp )-\mathrm{CPM}(\text { spontaneous })}{\mathrm{CPM}(\text { maximum })-\mathrm{CPM}(\text { spontaneous })} \times 100$.

For proliferation-inhibiting assay, the cell growth of MCA-38 tumor cells was cultured with NK supernatant (NK-sup, 1:4) in the presence or absence of neutralizing antibodies for $72 \mathrm{~h}$ and then checked using 3-(4,5-dimethylthiazol-2-yl)-2,5-diphenyl tetrazolium bromid (MTT) assay (Boehringer Mannheim, Mannheim, Germany) depending on the attached protocol. Rapidly growing MCA-38 cells were harvested, counted, and added to 96-well microtiter plates at $5.0 \times 10^{3}$ cells/well in a volume of $200 \mu \mathrm{l}$ containing NK supernatant (final 1:4) in the presence or absence of anti-IFN $\gamma$ monoclonal antibody (clone 2E6; a gift from Dr. Kenny, NCI-FCRDC, Frederick, MD) antiTGF $\beta$ (1011), or anti-TNF $\alpha$ (2E2, a gift from the Biological Response Modifiers Program Repository) at a dosage of $5 \times 10^{3}$ or $5 \times$ $10^{4} \mathrm{NU} / \mathrm{ml}$. After $72 \mathrm{~h}$ the growth inhibition was measured using MTT kit as described in the attached protocol. The percentage growth inhibition was calculated as followed:

percentage growth inhibition $=\left(1-\frac{\mathrm{A} 570 \text { of treated cells }}{\mathrm{A} 570 \text { of untreated cells }}\right) \times 100$.

Pathologic examination of tissue. Tissues from the respective groups were also taken for histopathologic analysis. Routinely liver, whole gut, and skin specimens were placed in 10\% neutral-buffered formalin, imbedded in paraffin, and 6- $\mu \mathrm{m}$ thick samples were sectioned and stained with hematoxylin and eosin (H\&E). The histologic analysis was performed by a veterinary pathologist blinded to the treatment regimens. Special attention was given to the liver focusing on periductal or perivascular lymphoid cell infiltrates, degeneration of hepatocyte and biliary epithelial cells. In the gut special attention was given to epithelial cell degeneration, mucosal erosion or ulceration, and intraepithelial lymphocytes. The lesions were graded by a veterinary pathologist without knowledge of the treatment groups.

Statistical analysis. The two-sample $t$ test was used to compare the results. Survival data were plotted by the Kaplan-Mier method and analyzed by the Log-Rank test. A $P$ value $<0.05$ was considered significant.

\section{Results}

Activated NK cells allogeneic of donor type prevent $G v H D$ after allogeneic BMT. C57BL/6 $\left(\mathrm{H}-2^{\mathrm{b}}\right)$ mice received an allogeneic BMT with full MHC-disparate BMC from BALB/c $\left(\mathrm{H}-2^{\mathrm{d}}\right)$ mice. The cotransfer of allogeneic $\mathrm{SC}$ with the $\mathrm{BMC}$ induced significant weight loss and skin GvHD manifested as skin alopecia with scleroderma. All mice succumbed to GvHD by $30 \mathrm{~d}$ (Fig. 1). To determine the effects of activated NK cells on GvHD, IL-2-activated NK cells of donor type were also administered with allogeneic BMC and SC. Mice receiving NK cells also received IL-2 for $3 \mathrm{~d}$ as it has been previously demonstrated that when NK cells are cultured in IL-2 they become 


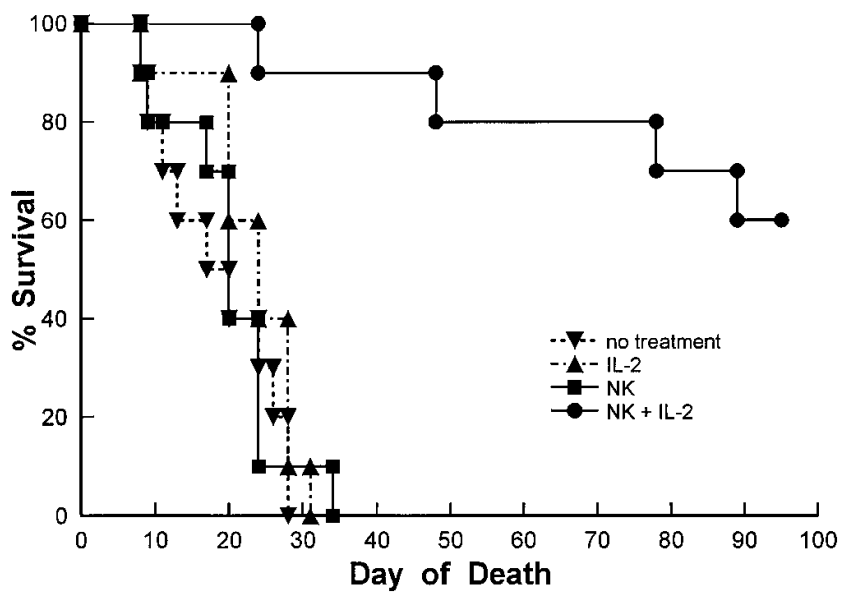

Figure 1. Activated NK cells of donor type prevents GvHD. Recipient mice $\left(\mathrm{B} 6, \mathrm{H}-2^{\mathrm{b}}\right)$ were lethally irradiated and injected with allogeneic $\left(\mathrm{BALB} / \mathrm{c}, \mathrm{H}-2^{\mathrm{d}}\right) \mathrm{BMCs}\left(1 \times 10^{7}\right.$ cells $)$, and SCs $\left(2 \times 10^{7}\right.$ cells $)$ i.v. Mice in some groups were injected with $2 \times 10^{7}$ cells of rhIL-2-activated NK cells of donor type (SCID, H-2 ${ }^{\text {d }}$ ) i.p. on day 0 . Mice in some groups were injected with $5 \times 10^{4} \mathrm{IU}$ of rhIL-2 i.p. on day 0,1 , and 2 . No treatment, without rhIL-2 nor NK cells; no treatment vs $N K+I L-2$, $P<0.0005$. A representative experiment is shown with 10 mice per group.

dependent on it for retaining function after in vivo transfer (8). When the mice received activated NK cells of donor type and IL-2, survival was further prolonged in these recipients, compared with mice not receiving NK cells (Fig. 1). Histopatholog-

A
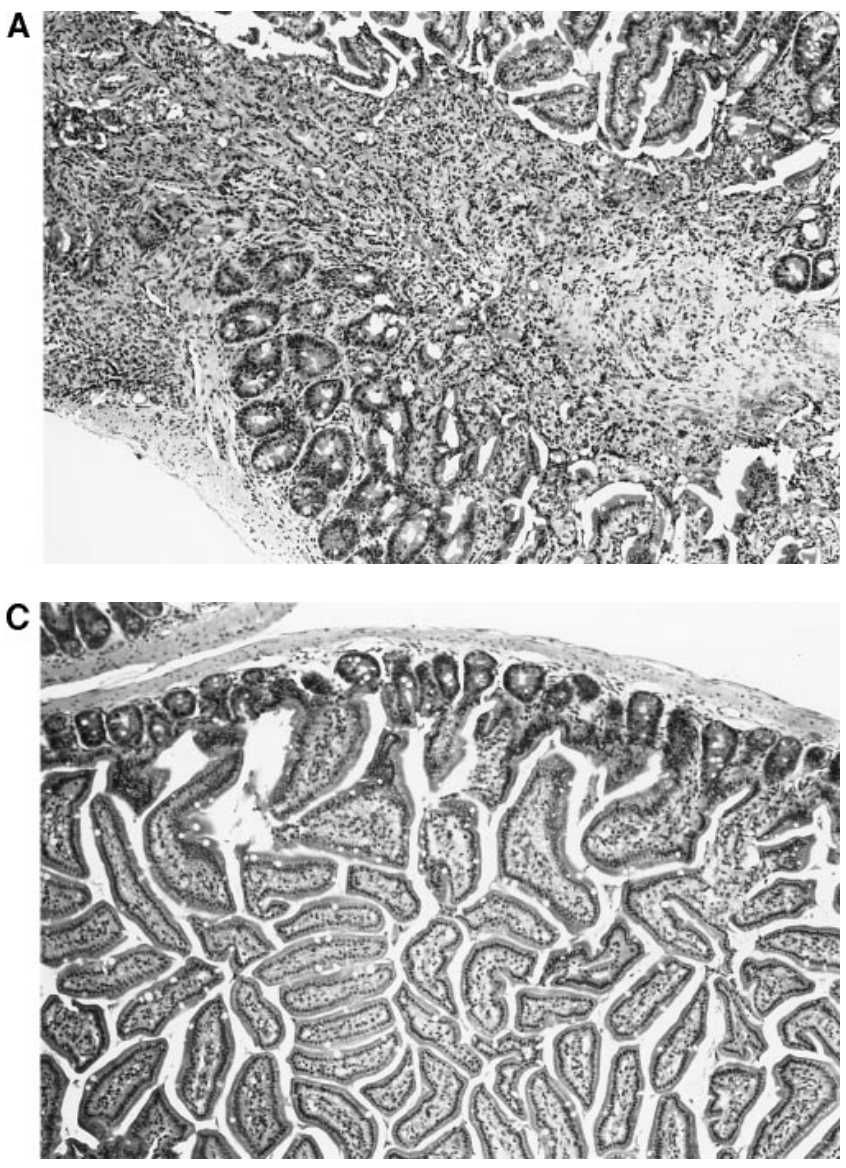

ical study of the recipients receiving SC alone showed extensive infiltration of inflammatory cells with associated cellular necrosis, e.g., severe gut GvHD (Fig. 2, $A$ and $B$ ). However, mice also receiving activated NK cells showed no infiltration of inflammatory cells with normal structure of gut being noted at this timepoint (Fig. 2 C). In 11 separate experiments the administration of activated NK cells significantly delayed the onset of GvHD with an average of $20-30 \%$ being long term (>100 d) survivors demonstrating no evidence of GvHD (Table I). When donor chimerism was assessed in the surviving recipients, it was found to be comprised of $>95 \%$ donor cells in all recipients indicating that stable engraftment was achieved. When the NK cells were irradiated with 3,000 cGy before injection, no effect on GvHD was observed (data not shown). These results indicate that activated NK cell of donor-type can inhibit or delay the occurrence of GvHD after allogeneic BMT in mice.

Anti-TGF $\beta$ monoclonal antibody abrogated the preventive effects of activated NK cells. NK cells have been previously shown to produce numerous cytokines including TGF $\beta$, IFN $\gamma$, TNF $\alpha$, GM-CSF and G-CSF (8). It has been also demonstrated that activated NK cells can inhibit a mixed lymphocyte reaction (MLR) in vitro due to the production of TGF $(12)$. We therefore wanted to determine if the mechanism of the prevention of GvHD by activated NK cells was due to TGFB. We administered neutralizing antibodies to TGFß in vivo. Treatment with anti-TGF $\beta$ monoclonal antibody (1D11) for $3 \mathrm{~d}$ significantly $(P<0.01)$ shortened the survival compared with mice receiving NK cells and IL-2 (Fig. 3). Interestingly, mice receiving the antibody alone demonstrated a significant

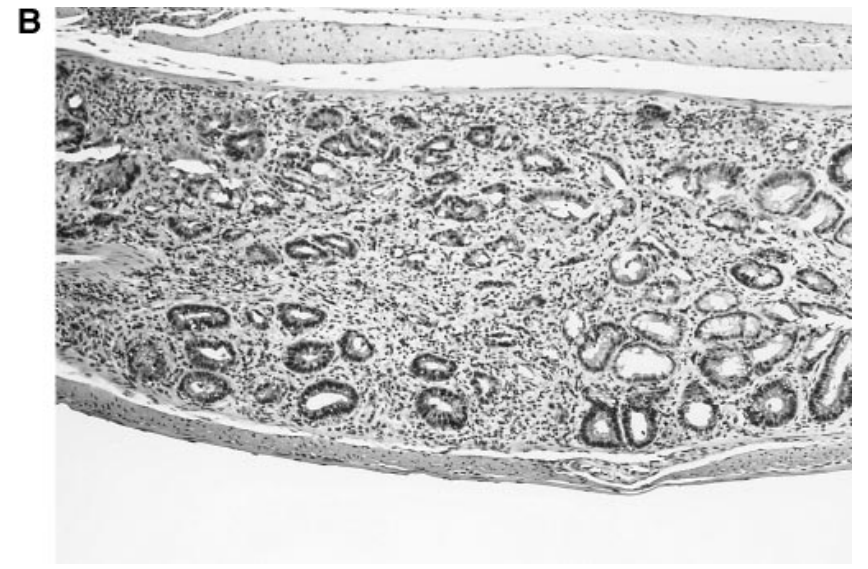

Figure 2. Transfer of activated NK cells of donor type does not show the findings of GvHD histopathologically. Recipient mice (B6, H-2 ${ }^{\mathrm{b}}$ ) were lethally irradiated and injected with allogeneic (BALB/c, H-2 $)$ BMCs $\left(1 \times 10^{7}\right.$ cells $)$, and SCs $\left(2 \times 10^{7}\right.$ cells $)$ i.v. Mice in one group were injected with $2 \times 10^{7}$ cells of rhIL-2-activated NK cells of donor type (SCID, H- ${ }^{\mathrm{d}}$ ) i.p. on day 0 , and injected with $5 \times 10^{4}$ IU of rhIL-2 i.p. on day 0,1 , and 2 . On day 14 mice were killed and gut sections were harvested and stained with H\&E. ( $A$ and $B$ ) gut from the mice without NK cells nor rhIL-2 exhibited necrosis of epithelial cells, dropout of entire glands, submucosal fibrosis, and inflammatory infiltrates consistent with gut GvHD. (C) gut from the mice with NK cells and rhIL-2 demonstrated normal gut structures and no inflammatory cells were detected. 
Table I. Effects of IL-2-activated NK Cells on Long Term Survival after Allogeneic BMT in Mice

\begin{tabular}{lcc}
\hline & & Number of mice surviving after $100 \mathrm{~d}$ \\
\cline { 3 - 3 } Experiment & BMC+SC & BMC + SC + NK cells \\
\hline 1 & 0 & $8 / 10$ \\
2 & 0 & 0 \\
3 & 0 & $6 / 10$ \\
4 & 0 & $2 / 10$ \\
5 & 0 & $3 / 10$ \\
6 & 0 & 0 \\
7 & 0 & $2 / 10$ \\
8 & 0 & $6 / 10$ \\
9 & 0 & 0 \\
10 & 0 & $1 / 10$ \\
11 & 0 & $2 / 10$ \\
\end{tabular}

All experiments had 10 mice per group and the BMT was performed as described in Methods.

increase in morbidity due to severe GvHD compared with recipients receiving $\mathrm{BMC}$ and $\mathrm{SC}$ indicating that host production of TGF $\beta$ was also important in regulating GvHD in the recipients. The data demonstrate that the preventive effects of activated NK cells were completely abrogated by the administration of anti-TGF $\beta$ monoclonal antibody. This indicated that TGF $\beta$ is at least partially responsible for the protection resulting from the activated NK cells. Interestingly, when we exogenously administered TGF $\beta$ (1.0 or $0.1 \mu \mathrm{g}$ i.p. daily on day 0,1 , 2 , and 3 after the BMT) systemically, no protective effect from GvHD resulted and the mice succumbed similar to control recipients (Fig. 4). Thus, TGFß appears to be a critical mediator

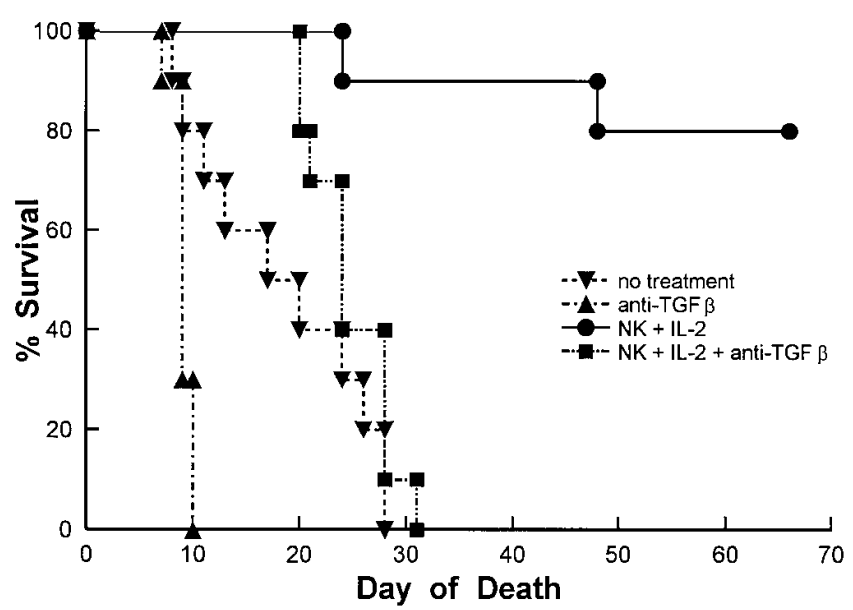

Figure 3. Anti-TGF $\beta$ monoclonal antibody abrogates the preventive effects of activated NK cells. Recipient mice $\left(\mathrm{B} 6, \mathrm{H}-2^{\mathrm{b}}\right)$ were lethally irradiated and injected with allogeneic $\left(\mathrm{BALB} / \mathrm{c}, \mathrm{H}-2^{\mathrm{d}}\right) \mathrm{BMCs}(1 \times$ $10^{7}$ cells $)$, and SCs $\left(2 \times 10^{7}\right.$ cells $)$ i.v. Mice in some groups were injected with $2 \times 10^{7}$ cells of rhIL-2-activated NK cells of donor type (SCID, H-2 ${ }^{\text {d }}$ i.p. on day 0 , and injected with $5 \times 10^{4} \mathrm{IU}$ of rhIL-2 i.p. on day 0,1 , and 2. Mice in one group were injected with $80 \mu \mathrm{g}$ of antiTGF $\beta$ monoclonal antibody i.p. on day 0,2 , and 4 . No treatment, without rhIL-2 nor NK cells. $N K+I L-2$ vs $N K+I L-2+$ anti-TGF $\beta, P<0.01$.

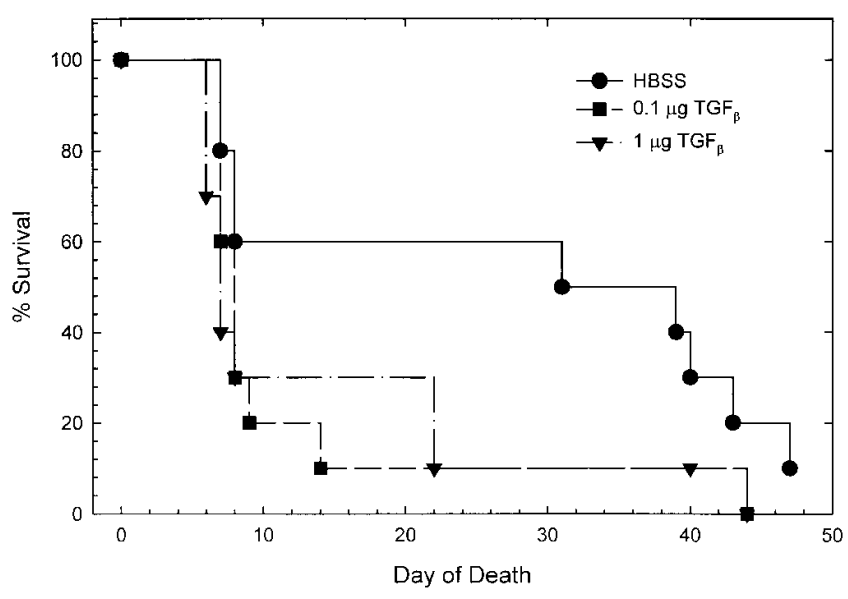

Figure 4. Exogenous TGF $\beta$ does not prevent GvHD. Recipient mice $\left(\mathrm{B} 6, \mathrm{H}-2^{\mathrm{b}}\right)$ were lethally irradiated and injected with allogeneic $\left(\mathrm{BALB} / \mathrm{c}, \mathrm{H}-2^{\mathrm{d}}\right) \mathrm{BMCs}\left(1 \times 10^{7}\right.$ cells $)$, and SCs $\left(2 \times 10^{7}\right.$ cells $)$ i.v. Mice in some groups were injected with 1.0 or $0.1 \mu \mathrm{g}$ of TGF $\beta$ on day $0,1,2,3$. No treatment, without rhIL-2 nor NK cells. No treatment vs $T G F \beta$, not significant.

for the protective effects of NK cells after BMT. Furthermore, adoptive immunotherapy using NK cells appear superior than systemic administration of this cytokine in preventing GvHD.

Later administration of IL-2 and not activated NK cells promotes $G v H D$. We found that administration of activated NK cells with IL-2 on day 0 prevented the occurrence of GvHD. However, when activated NK cells and IL-2 were administrated later than $3 \mathrm{~d}$ after BMT, the mice succumbed at earlier time points compared to control mice from GvHD (Fig. 5). To understand the timing of the preventative effects of NK cells, we administered NK cells and IL-2 at different time points. As

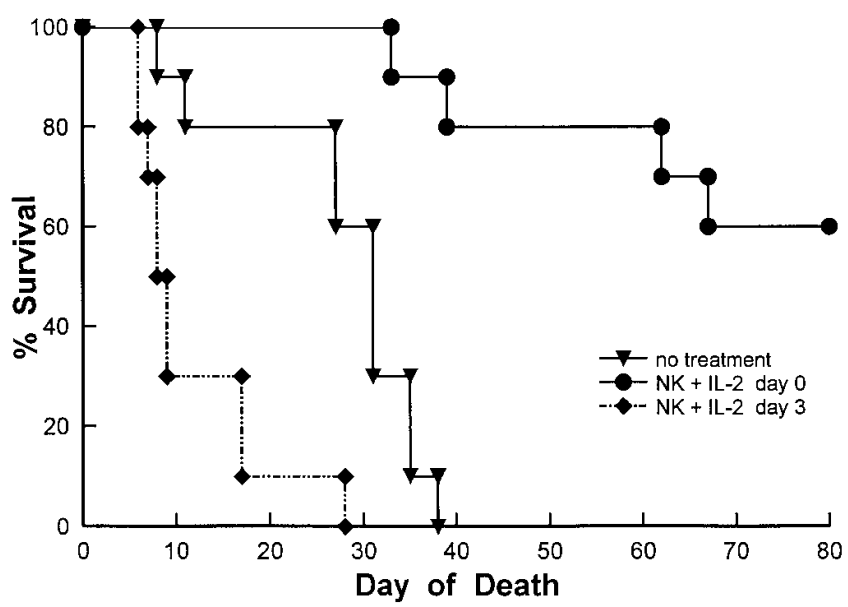

Figure 5. Later administration of rhIL-2 with NK cells promotes GvHD. Recipient mice (B6, H-2 $2^{\text {b }}$ ) were lethally irradiated and injected with allogeneic $\left(\mathrm{BALB} / \mathrm{c}, \mathrm{H}-2^{\mathrm{d}}\right) \mathrm{BMCs}\left(1 \times 10^{7}\right.$ cells $)$, and SCs $\left(2 \times 10^{7}\right.$ cells $)$ i.v. Mice were injected with $2 \times 10^{7}$ cells of rhIL-2activated NK cells of donor type (SCID, H-2 ${ }^{\text {d }}$ ) i.p. on day 0 or 3 , with $5 \times 10^{4}$ IU of rhIL-2 i.p. on day $0,1,2$, or on day $3,4,5$. No treatment, without rhIL-2 nor NK cells. $N K+I L-2$ day 0 , NK cells on day 0 and IL-2 on day $0,1,2$. NK+IL-2 day 3 , NK cells on day 3 and IL-2 on day $3,4,5$. No treatment vs $N K+I L-2$ day $3, P<0.005$. 


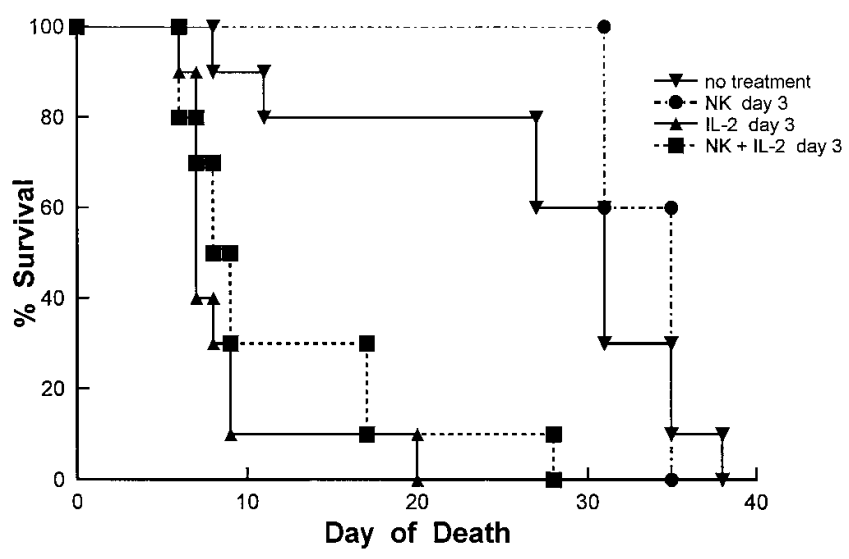

Figure 6. Late administration of rhIL-2 and not NK cells, promotes GvHD. Recipient mice (B6, H-2 $\left.{ }^{b}\right)$ were lethally irradiated and injected with allogeneic $\left(\mathrm{BALB} / \mathrm{c}, \mathrm{H}-2^{\mathrm{d}}\right)$ BMCs $\left(1 \times 10^{7}\right.$ cells $)$, and SCs $\left(2 \times 10^{7}\right.$ cells $)$ i.v. Mice in some groups were injected with $2 \times 10^{7}$ cells of rhIL-2-activated NK cells of donor type (SCID, H-2 ${ }^{\mathrm{d}}$ ) i.p. on day 3. Mice in some groups were injected with $5 \times 10^{4} \mathrm{IU}$ of rhIL-2 i.p. on day $3,4,5$. No treatment, without rhIL-2 nor NK cells. $I L-2$ day 3 , IL-2 on day $3,4,5$. $N K$ day 3 , NK cells on day $3 . N K+I L-2$ day 3 , NK cells on day 3 and IL-2 on day $3,4,5$. No treatment vs $I L-2$ day 3 ; $P<0.005 ;$ no treatment vs $N K+I L-2$ day $3, P<0.005 ;$ no treatment vs NK day 3 , not significant.

shown in Fig. 6, administration of IL-2 on day 3, 4, 5 with or without NK cells on day 3 shortened the survival significantly $(P<0.005)$, while administration of NK cells alone on day 3 did not appear to affect the survival. These results suggest that later administration of IL-2 may promote GvHD and that there appears to be a critical window in which the administration of activated NK cells can prevent GvHD.

Activated NK cells promote GvT and inhibit GvHD in advanced tumor-bearing mice. To determine the influence of the activated NK cells on both GvHD and GvT, a GvHD/GvT model was established giving allogeneic $\mathrm{T}$ cells (SC) with the $\mathrm{BMC}$ to tumor-bearing B6 mice after the BMT. B6 mice were given MCA-38 tumor cells, and $10 \mathrm{~d}$ later an allogeneic BMT was performed. At the time of treatment with BMT, mice had evidence of extensive lung metastasis. Effects on survival were noted (Fig. 7) and $14 \mathrm{~d}$ after BMT mice in some groups were examined for the extent of lung metastasis (Fig. 8). Mice receiving BMT alone demonstrated a significant increase in survival indicating that the cytoreductive therapy was effective in reducing but not eliminating the tumor (Fig. 7). Interestingly, mice receiving allogeneic $\mathrm{SC}$ and $\mathrm{BMC}$ had significantly less lung metastasis than mice receiving BMC alone (Fig. 8), but survival was not affected due to the occurrence of acute GvHD in the recipients (Table I). Administration of activated NK cells of donor type with SC after BMT produced the greatest increase in survival $(P<0.05$, Fig. 7$)$ and the lowest number of lung metastasis $(P<0.05$, Fig. 8$)$, demonstrating that the combination of activated NK cells with SC exerts significant antitumor effects after allogeneic BMT. Importantly, histological assessment indicated that activated NK cells of donor type also prevented GvHD in tumor-bearing mice (Table II). These results demonstrate that $\mathrm{T}$ cells can mediate both GvT and GvHD effects but they cannot be dissociated, whereas ac-

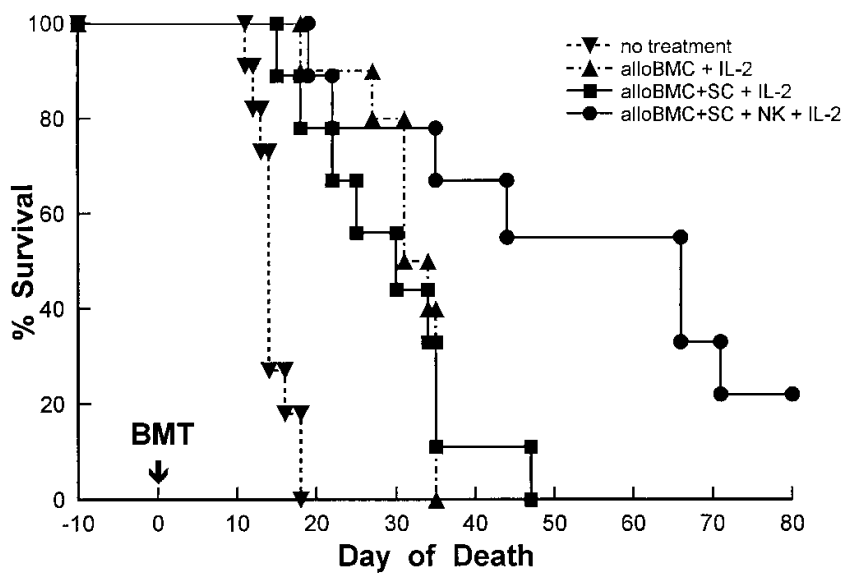

Figure 7. Activated NK cells of donor type exert antitumor effects with allogeneic T cells. Recipient mice (B6, H-2 ${ }^{\text {b }}$ ) were injected with $1 \times 10^{5}$ cells of MCA-38 tumor cells on day -10 . Mice in some groups were lethally irradiated and injected with allogeneic (BALB/c, H-2 ${ }^{\mathrm{d}}$ ) BMCs $\left(1 \times 10^{7}\right.$ cells $)$ with or without SCs $\left(2 \times 10^{7}\right.$ cells $)$ i.v. Mice in some groups were injected with $5 \times 10^{4}$ IU of rhIL-2 i.p. on day $0,1,2$ with or without activated NK cells of donor type (SCID, H- $2^{\mathrm{d}}$ ) i.p. on day 0. No treatment, without irradiation nor BMT; alloBMC, with irradiation, allogeneic $\mathrm{BMCs}$; allo $B M C+S C+I L-2$, with irradiation, allogeneic BMCs, allogeneic SCs, and IL-2; alloBMC+SC+NK+IL-2, with irradiation, allogeneic BMCs, allogeneic SCs, NK cells, and IL-2. no treatment vs alloBMC+SC+NK+IL-2,P<0.05; allo$B M C+I L-2$ vs alloBMC+SC+NK+IL-2,P<0.05; alloBMC+ $S C+I L-2$ vs alloBMC+SC+NK+IL-2,P<0.05.

tivated NK cells exert potent antitumor effects after allogeneic $\mathrm{BMT}$ replete with $\mathrm{T}$ cells in the donor inoculum without inducing GvHD.

The mechanism underlying the antitumor effects of $N K$ cells may be by the production of IFN $\gamma$. We found that activated NK cells were only weakly cytotoxic against MCA-38 cell in vitro (Fig. $9 A$ ). To determine the potential mechanism underlying their in vivo antitumor effects, MCA-38 tumor cells were cultured for $72 \mathrm{~h}$ with $\mathrm{NK}$ cell culture supernatants. Because $\mathrm{NK}$ cells produce interferon, a neutralizing anti-IFN $\gamma$ monoclonal antibody was also used to ascertain if potential inhibitory effects could be attributed to this cytokine. The data demonstrate that incubation of the tumor cells with the NK cell supernatants significantly inhibited the proliferation of MCA38 cells $(P<0.000005)$ (Fig. $9 B)$. The data also demonstrate that the inhibition could be partially abrogated by the antibody to IFN $\gamma(P<0.0005)$ (Fig. $9 B)$. Antibodies to TGF $\beta$ and TNF did not significantly abrogate inhibition in vitro (data not shown). These data suggest that IFN $\gamma$ produced by NK cells may play an important role with their antitumor effects in vivo.

\section{Discussion}

BMT offers promise for the treatment of neoplasia and has been increasingly applied for the treatment of solid tumors. Allogeneic BMT appears superior to autologous BMT in antitumor efficacy, however, serious problems exist that currently hinder its application. The occurrence of GvHD remains the most significant obstacle in allogeneic BMT. A primary issue 


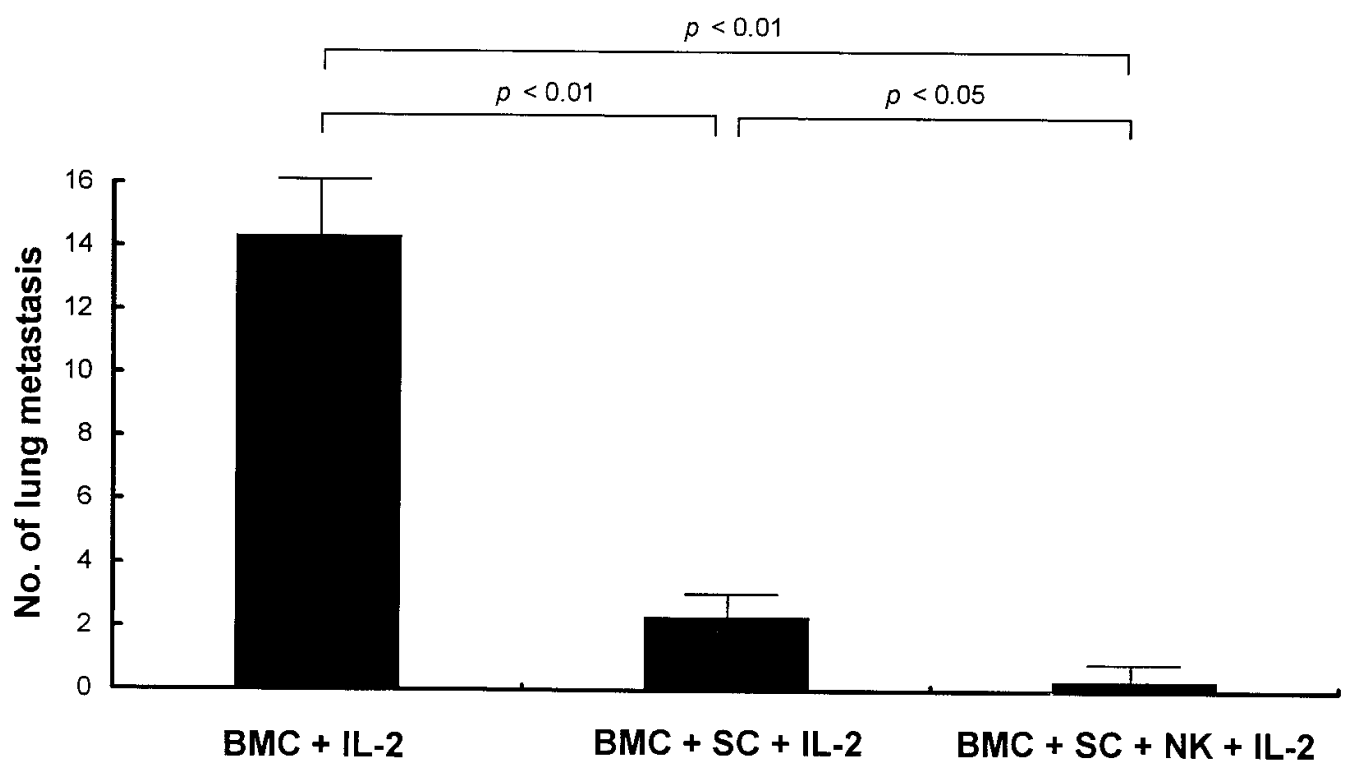

Figure 8. Activated NK cells decrease the number of lung metastasis of tumor-bearing mice. Recipient mice (B6, $\mathrm{H}-2^{\mathrm{b}}$ ) were injected with $1 \times 10^{5}$ cells of MCA- 38 tumor cells on day -10 . Mice in some groups were lethally irradiated and injected with syngeneic (B6) or allogeneic $\left(\mathrm{BALB} / \mathrm{c}, \mathrm{H}-2^{\mathrm{d}}\right) \mathrm{BMCs}(1 \times$ $10^{7}$ cells $)$ with SCs $\left(2 \times 10^{7}\right.$ cells) i.v. Mice in one group were injected with $5 \times 10^{4} \mathrm{IU}$ of rhIL-2 i.p. on day $0,1,2$ with activated NK cells of donor type (SCID, H-2 ${ }^{\text {d }}$ i.p. on day 0 . On day 14 , the lungs of the recipient were harvested, placed into Bouin's solution, and then the tumor nodules on the lung surface were counted. concerns whether GvHD and GvT are dissociable phenomena, as current treatments to control GvHD also lead to diminished GvT effects. The results presented here indicate that the two processes can be dissociated depending on the effector cell being examined. Allogeneic $\mathrm{T}$ cells induced both GvT and GvHD in the tumor-bearing recipients with the mice ultimately succumbing to GvHD. However, NK cells were capable of promoting GvT while inhibiting GvHD. GvHD has

Table II. Activated NK Cells of Donor Type Inhibit GvHD of Liver, Gut, and Skin on Histopathological Evaluation of Tumor-bearing Mice

\begin{tabular}{|c|c|c|}
\hline Organ/diagnosis & $\mathrm{BMC}+\mathrm{SC}+\mathrm{IL}-2$ & $\begin{array}{c}\mathrm{BMC}+\mathrm{SC}+ \\
\mathrm{NK}+\mathrm{IL}-2\end{array}$ \\
\hline \multicolumn{3}{|l|}{ Liver } \\
\hline Inflammation, subacute & $3 \mathrm{M}, 2 \mathrm{M}, 3 \mathrm{M}$ &,------- \\
\hline Oval cell hyperplasia & $2 \mathrm{M}, 2 \mathrm{M}, 2 \mathrm{M}$ &,------- \\
\hline Vacuolation, hepatocellular & $2 \mathrm{M},----, 2 \mathrm{M}$ & ----, ----, ----, \\
\hline \multicolumn{3}{|l|}{ Gut } \\
\hline Small intestine-crypt cell hyperplasia & $2 \mathrm{M}, 2 \mathrm{M}, 2 \mathrm{M}$ &,------- \\
\hline Small intestine-villous sloughing & $2 \mathrm{M}, 2 \mathrm{M}, 2 \mathrm{M}$ & ----, ----, ----, \\
\hline Colon-proliferative colitis & $2 \mathrm{M}, 3 \mathrm{M}, 3 \mathrm{M}$ &,,,------------ \\
\hline Large intestine-ulcer/erosion & $1 \mathrm{M}, 1 \mathrm{M}, 1 \mathrm{M}$ & ----, ----, ----, \\
\hline Colon-inflammation, granulomatous & $3 \mathrm{M},----, 2 \mathrm{M}$ & ----, ----, ----, \\
\hline Cecum-proliferative typhlitis & $2 \mathrm{M}, 3 \mathrm{M}, 3 \mathrm{M}$ &,------- \\
\hline \multicolumn{3}{|l|}{ Skin } \\
\hline Inflammation, chronic active & $2 \mathrm{M}, 2 \mathrm{M}, 3 \mathrm{M}$ & ----, ----, ----, \\
\hline Squamous hyperplasia & $2 \mathrm{M}, 2 \mathrm{D}, 2 \mathrm{M}$ & ----, ----, ----, \\
\hline Dermal melanosis & $2 \mathrm{M},----, 2 \mathrm{M}$ & ----, ----, ----, \\
\hline Exudate crust & $----, 3 \mathrm{M}, 3 \mathrm{M}$ & ----, ----, ----, \\
\hline Hyperkeratosis & $---, 2 \mathrm{M}, 2 \mathrm{M}$ & ----, ----, ----, \\
\hline Ulcer/erosion & $---, 1 \mathrm{M}, 1 \mathrm{M}$ &,,,------------ \\
\hline
\end{tabular}

Grading information: 1, minimal; 2, mild; 3, moderate; 4, severe; M, multifocal; D, diffuse; ----, negative. Mice were assessed $14 \mathrm{~d}$ after BMT. been shown to be caused by the specific attack of donor T cells against alloantigens of the recipient (4). NK cells, being MHC unrestricted, are not capable of initiating GvHD. However, they may play a role in the ensuing pathology of GvHD initiated by the donor $\mathrm{T}$ cells. The protective effects of NK cells could only be obtained if they were transferred early after BMT indicating their ability to suppress the sensitization stage of GvHD during which the donor T cells are first reacting to the alloantigens on the host. Once the $\mathrm{T}$ cells become primed and expand, an amplification stage appears to occur in which the NK cells are no longer protective and may, in fact, be deleterious due to the inflammatory cytokines (i.e., IL-1, TNF, etc.) that they can produce. This may reconcile the previous literature concerning the role of $\mathrm{NK}$ cells in GvHD in which some groups have reported they promote GvHD (13) and some reporting that they are capable of inhibiting it (8). LAK cells, asialo $\mathrm{GM} 1^{+}$cells, IL-2, IL-12 have all been reported to either inhibit and promote GvHD depending on the model used (13-16). The mechanisms underlying these effects remain unclear as these treatments affect a variety of effector and target cell populations (i.e., T cells, monocytes, NK cells).

While IL-2 has been suggested to inhibit GvHD in some laboratories, conflicting reports existed concerning its role in allogeneic BMT, with reports indicating that IL-2 administration promoted GvHD after clinical use (16). While our studies demonstrated no significant protection after administering IL-2 alone, we did use less than the original report has used and we have seen some slight protective effects in some experiments (data not shown). In addition, Sykes et al. have shown that the protective effects of high dose IL-2 in their model system was not due to NK cells (17). However, they have recently reported that IL-12 also prevented GvHD (15) and this may be by NK cell induction. Regardless of the potential similarities and differences concerning the cytokine effects and the effects of NK cells, the use of adoptively transferred NK cells may offer additional advantages over systemic administration of cytokines. The ability of exogenous cytokines, even with high doses, to induce NK activity after systemic administration may 

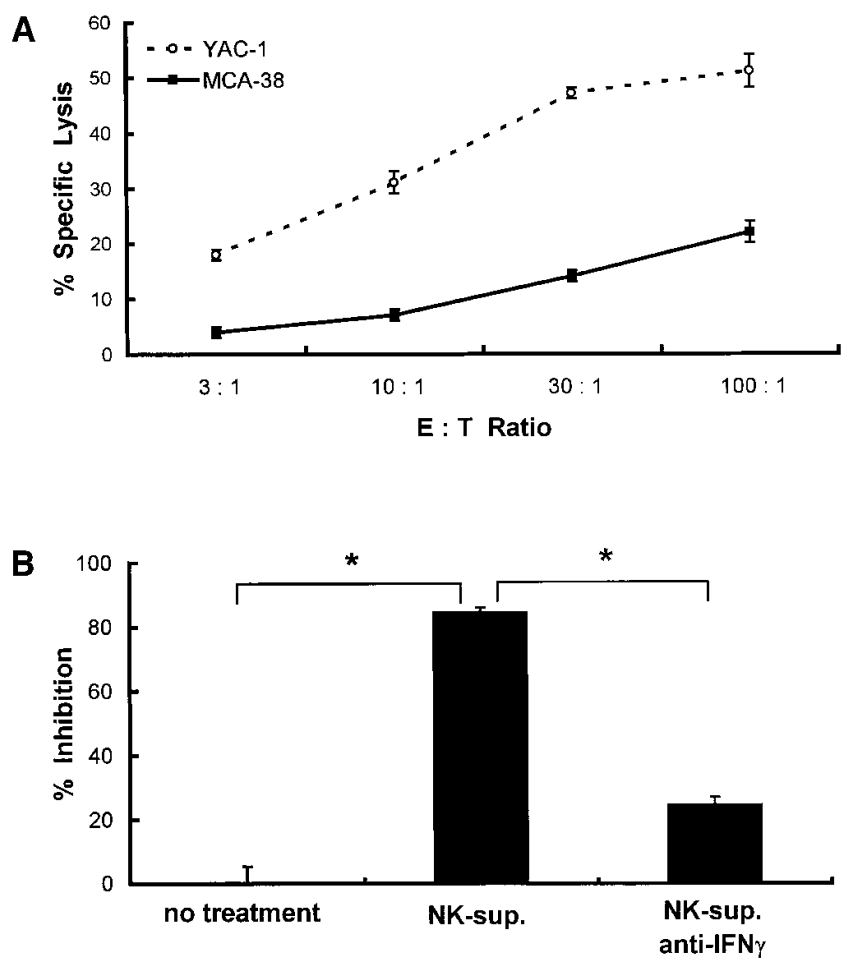

Figure 9. Direct and indirect antitumor effects of NK cells against MCA-38 cells. (A) MCA-38 tumor cells and YAC-1 (mouse NK cell sensitive) cells were labeled with ${ }^{51} \mathrm{Cr}$ for $1 \mathrm{~h}$. Then $5 \times 10^{3}$ cells/well of labeled target cells were mixed with rhIL-2-activated NK cells obtained from SCID mice $\left(\mathrm{H}-2^{\mathrm{d}}\right)$ to achieve effector/target cell ratios of 3:1, 10:1, 30:1, and 100:1. After standard $4 \mathrm{~h}$ incubation, the supernatant were harvested and analyzed on a gamma counter. The percentage specific lysis was calculated as described in the Methods section. (B) MCA-38 tumor cells $\left(2.5 \times 10^{4}\right.$ cells $\left./ \mathrm{ml}\right)$ were cultured for $72 \mathrm{~h}$ at $37^{\circ} \mathrm{C}$ with $25 \%$ diluted supernatant of the media in which NK cells were cultured ( $N K$-sup.), and added MTT for the last $4 \mathrm{~h}$. Some groups were added with $5 \times 10^{3}$ or $5 \times 10^{4} \mathrm{NU} / \mathrm{ml}$ of anti-IFN $\gamma$ monoclonal antibody. After lysing the cells with $1 \%$ SDS, OD were counted with ELISA reader at A.570. $* P<0.0005$.

be less efficient than the adoptive transfer of these cells immediately after BMT. This may be important since in both the high dose IL-2 model and the adoptive transfer of NK cells, the time at which treatment is initiated appears critical (18). Another potential advantage of using transferred NK cells is that the exacerbation of GvHD we detected when the NK cells were administered at later time points was due to the IL-2 that was administered and not the NK cells. Thus it may be safer to use activated NK cells with lower amounts of IL-2 or other cytokines such as IL-15 or IL-12 rather than use high dose IL-2 and risk exacerbating GvHD due to the narrow window where protection can be achieved. This narrow window of NK cell mediated protection may also be easily missed in an outbred population in which various individuals may have different kinetics for the sensitization stage of GvHD. An alternate approach would be to administer the activated NK cells with a T-depleted BMC graft. In this manner the activated NK cells would facilitate the engraftment of the donor marrow and provide the GvT effects without the risk of GvHD. Ultimately, the NK cells would be given with a $\mathrm{T}$ cell replete graft, as the mechanisms underlying their protective effect become more completely understood and optimized. For example, ours demonstrate the administration of activated NK cells primarily delayed GvHD with some recipients demonstrating no evidence of GvHD at longer time points. More work must be done to ascertain if the administration of NK cells, possibly with other means to suppress GvHD (i.e., blockade of costimulatory molecules can result in greater protection and subsequent tolerance).

TGF $\beta$ has potent immunoregulatory properties ranging from effects on the growth and differentiation of primitive stem cells to the differentiated functions of immune effector cells (19). It has been reported that NK cells inhibit a mixed lymphocyte reaction (MLR) in vitro due to the production of TGF $\beta$ (12). Here, we have extended these studies by demonstrating that treatment with anti-TGF $\beta$ monoclonal antibody completely abrogates the protective effects produced by NK cells. It is not clear whether the NK cells are producing the TGF $\beta$ or are inducing other cells to make it. Interestingly, it appears that the recipients receiving anti-TGF $\beta$ monoclonal antibody without NK cells succumbed earlier to GvHD than control recipients suggesting that host-derived TGF $\beta$ may also be important in regulating the pathology of GvHD. The inability of exogenous TGF $\beta$ to protect the recipients from GvHD may be due to systemic toxicity or that other immune mechanisms may also be involved in the protection offered by the NK cells. Alternatively, the sustained local release of cytokines by the transferred NK cells may allow for a greater therapeutic window over the systemic administration of cytokines with relatively rapid clearance rates. Additionally, other cytokines produced by $\mathrm{NK}$ cells (i.e., IFN $\gamma, \mathrm{TNF} \alpha, \mathrm{G}-\mathrm{CSF}$ ) may also play a role in the suppression of GvHD. Indeed, we have preliminary data that use of donor cell obtained from IFN $\gamma$ knock-out mice succumb earlier from GvHD than cells obtained from normal controls, suggesting that IFN $\gamma$ may also play an immunosuppressive role in GvHD. Attempts to determine if neutralizing antibodies to IFN $\gamma$ could abrogate the protective effects of NK cells have thus far been negative (data not shown). However, more work needs to be performed examining the role of the other immunomodulatory cytokines produced by NK cells.

We also demonstrate here that IL-2-activated NK cells of donor type after allogeneic BMT produce significant GvT effects in mice with an advanced tumor burden. Previous reports using in vivo depletion of NK cells have suggested that NK cells are responsible for potent antitumor effects $(20,21)$. By adoptively transferring a pure population of activated NK cells we demonstrate that NK cells can be therapeutically applied in the treatment of cancer. By using a solid tumor model (a colon adenocarcinoma, MCA-38) in which the tumor is highly invasive with extensive metastasis to lung at the time of treatment, a more applicable model mimicking a clinical scenario was obtained. In this model, the activated NK cells would be used to remove the minimal residual disease that ultimately comes back after extensive cytoreductive conditioning regimens. It is also of interest that the MCA-38 tumor used was only weakly lysed by the activated NK cells. The production of cytokines by the NK cells (i.e., IFN, TNF $\alpha$, etc.) may be an alternate, and possibly primary, mean by which the NK can exert antitumor effect in vivo. However, these same cytokines (i.e., IFN $\gamma$ ) may also play a role in instances where NK cells can contribute to the pathology of an ongoing GvHD (22). In this regard, by us- 
ing a solid tumor only weakly lysed by the NK cell, even more potent antitumor effects could be obtained if a lymphoma was used. NK cells have been previously demonstrated to preferentially lyse allogeneic lymphoma/leukemic cell lines $(23,24)$. Studies are currently underway to ascertain if the transfer of activated NK cells results in a greater graft-versus-leukemia effect after allogeneic BMT.

\section{Acknowledgments}

We thank Dr. Miriam Anver for assessing the GvHD pathology and Mr. Steve Stull for excellent technical assistance. We also thank Ms. Laura Knott for secretarial assistance and Drs. Bob Wiltrout and Craig Reynolds for critical review of the manuscript. Animal care was provided in accordance with the procedures outlined in the Guide for the Care and Use of Laboratory Animals (1985. National Institutes of Health publication No. 86-23).

\section{References}

1. Bortin, M.M., M.M. Horowitz, and A.A. Rimm. 1992. Increasing utilizations of allogeneic bone marrow transplantation: results of the 1988-1990 survey. Ann. Intern. Med. 116:505-509.

2. Armitage, J.O. 1994. Bone marrow transplantation. N. Engl. J. Med. 330: 827-829. 2652 .

3. Storb, R. 1995. Bone marrow transplantation. Transplant. Proc. 27:2649-

4. Ferrera, J.L., and H.J. Deeg. 1991. Graft-versus-host disease. N. Engl. J. Med. 324:667-672.

5. Goldman, J.M., R.P. Gale, M.M. Horowitz, J.C. Biggs, R.E. Champlin, E. Gluckman, R.G. Hoffmann, S.J. Jacobsen, A.M. Marmont, P.B. McGlave, et al. 1988. Bone marrow transplantation for chronic myelogenous leukemia in chronic phase: increased risk of relapse associated with T cell-depletion. Ann. Intern. Med. 108:806-811.

6. Marmont, A.M., M.M. Horowitz, R.P. Galem, K. Sobocinski, R.C. Ash, D.W. van Bekkum, R.E. Champlin, K.A. Dicke, J.M. Goldman, R.A. Good, et al. 1991. T-cell depletion of HLA-identical transplants in leukemia. Blood. 78: 2120-2123.

7. Murphy, W.J., C.W. Reynolds, P. Tiberghien, and D.L. Longo. 1993. Natural killer cells and bone marrow transplantation. J. Natl. Cancer Inst. 85:14751480 .

8. Murphy, W.J., J.R. Keller, C.L. Harrison, H.A. Young, and D.L. Longo. 1992. Interleukin-2-activated natural killer cells can support hematopoiesis in vitro and promote marrow engraftment in vivo. Blood. 80:670-677.
9. Levitt, L.J. 1991. Production of granulocyte/macrophage-colony-stimulating factor by human natural killer cells: modulation by the p75 subunit of the interleukin 2 receptor and by the CD2 receptor. J. Clin. Invest. 88:67-75.

10. Murphy, W.J., M. Bennett, V. Kumar, and D.L. Longo. 1992. Donortype activated natural killer cells promote marrow engraftment and B cell development during allogeneic bone marrow transplantation. J. Immunol. 148: 2953-2960.

11. Dasch, J.R., D.R. Pace, W. Waegell, D. Inenaga, and L. Ellingsworth. 1989. Monoclonal antibodies recognizing transforming growth factor- $\beta$. J. Immunol. 142:1536-1540.

12. Yamamoto, H., M. Hirayama, C. Genyeam, and J. Kaplan. 1994. TGF$\beta 1$ mediates natural suppressor activity of IL-2-activated lymphocytes. $J$. Immunol. 152:3842-3849.

13. Ghayur, R., T.A. Seemayer, and W.S. Lapp. 1988. Prevention of murine graft-versus-host disease by inducing and eliminating ASGM1 ${ }^{+}$cells of donor origin. Transplantation (Baltimore). 45:586-590.

14. Sykes, M., M.L. Romick, and D.H. Sachs. 1990. Interleukin 2 presents graft-vs-host disease while preserving the graft-vs-leukemia effect of allogeneic T cells. Proc. Natl. Acad. Sci. USA. 87:5633-5638.

15. Sykes, M., G.L. Szot, P.L. Nguyen, and D.A. Pearson. 1995. Interleukin12 inhibits murine graft-versus-host disease. Blood. 86:2429-2438.

16. Favrot, M.C., D. Floret, S. Negrier, P. Cochat, E. Bouffet, Z. Dacheng, C.R. Franks, T. Bijman, M. Brunat-Mentigny, I. Philip, and T. Philip. 1989. Systemic interleukin-2 therapy in children with progressive neuroblastoma after high dose chemotherapy and bone marrow transplantation. Bone Marrow Transplant. 4:499-503.

17. Sykes, M., and V.S. Abraham. 1992. The mechanism of IL-2 mediated protection against GVHD in mice. II. Protection occurs independently of NK/ LAK cells. Transplantation (Baltimore). 53:1063-1070.

18. Sykes, M., D.A. Pearson, and G.L. Szot. 1995. IL-2-induced GVHD protection is not inhibited by cyclosporin and is maximal when IL-2 is given over a $25 \mathrm{~h}$ period beginning on the day following bone marrow transplantation. Bone Marrow Transplant. 15:395-399.

19. Ruscetti, F.W., and M.A. Palladino. 1991. Transforming growth factor- $\beta$ and the immune system. Prog. Growth Factor Res. 3:159-162.

20. Trinchieri, G. 1989. Biology of natural killer cells. Adv. Immunol. 47: 187-196.

21. Habu, S., H. Fukai, K. Shimamura, M. Kasai, Y. Nagai, K. Okimura, and N. Tamaoki. 1981. In vivo effects of anti-asialo GM1. I. Reduction of NK activity and enhancement of transplanted tumor growth in nude mice. J. Immunol. 127:34-38.

22. Mowat, A.M. 1989. Antibodies to IFN- $\gamma$ prevent immunologically mediated intestinal damage in murine graft-versus-host reaction. Immunol. 68:18-24.

23. Zeis, M. 1995. Allogeneic NK cells as potent antileukemic effector cells after allogeneic bone marrow transplantation in mice. Transplantation (Baltimore). 59:1734-1736.

24. Glass, B., L. Uharek, M. Zeis, H. Loeffler, W. Mueller-Ruchholtz, and W. Gassman. 1996. Graft-versus-leukaemia activity can be predicted by natural cytotoxicity against leukaemia cells. Br. J. Haematol. 93:412-420. 